\title{
Viabilidade econômica de quatro intensidades de pastejo do capim Tanzânia na pecuária de corte $^{1}$
}

\section{Economic feasibility of four grazing intensities of Tanzania grass for beef cattle}

\author{
Rondineli Pavezzi Barbero ${ }^{2 *}$; Marco Aurélio Alves de Freitas Barbosa ${ }^{3}$; \\ Letícia Maria de Castro4; Edson Luis de Azambuja Ribeiro ${ }^{5}$; \\ Ivone Yurika Mizubuti ${ }^{5}$; Leandro das Dores Ferreira da Silva ${ }^{3}$; \\ Valter Harry Bumbieris Júnior ${ }^{3}$; Ana Paula de Souza Fortaleza ${ }^{3}$
}

\section{Resumo}

Foram avaliados os efeitos econômicos de quatro alturas de pastejo (20; 40; 60 e $80 \mathrm{~cm}$ ) do capim Tanzânia para bovinos de corte. A área total foi de 12 hectares divididos em piquetes de um hectare, com três repetições. Foram utilizados três bovinos, machos, Nelore por piquete, mais animais adicionais conforme necessidade de ajuste para as alturas pretendidas. A redução da altura do pasto permitiu maior taxa de lotação, onde, mesmo com redução no desempenho individual, houve maior produção por área. A taxa de juros atribuída sobre o capital do imóvel representou a maior parcela no custo final de produção. A participação das variáveis fixas apresentou comportamento linear positivo em função do aumento na altura dos pastos, se mostrando sensível à redução da escala de produção. Houve redução do custo de produção anual por hectare com aumento da altura de pastejo. Não foram detectadas diferenças nos indicadores econômicos determinados, e os quatro sistemas remuneraram o capital investido.

Palavras-chave: Agronegócio, lucro, rentabilidade, TIR, VPL

\begin{abstract}
Were evaluated the economic effects of four grazing heights $(20,40,60$ and $80 \mathrm{~cm})$ of Tanzânia grass for beef cattle. The total area was 12 acres divided into paddocks of one hectare, with three replications. We used three animals, males, Nelore per paddock, as more animals need additional adjustment to the height you want. The reduction in sward height allowed higher stocking rate, which, even with a reduction in individual performance, there was more beef production per area. The interest rate on capital given the property represented the largest share in the final cost of production. The participation of fixed variables showed a positive linear function of the increase in height from grazing, showing significant reduction of the production scale. A reduction in cost of production per hectare per year with increasing grazing height. No differences were found in certain economic indicators, and the four systems remunerate the capital invested.
\end{abstract}

Key words: Agribusiness, IRR, NPV, profit, profitability

1 Parte da dissertação de Mestrado em Ciência Animal, do primeiro autor, Universidade Estadual de Londrina, UEL, Londrina, PR.

2 Zootecnista, Discente de Doutorado de Pós-graduação em Zootecnia da Faculdade de Ciências Agrárias e Veterinárias do Campus de Jaboticabal, UNESP, Jaboticabal, SP. E-mail: rondinelibarbero@zootecnista.com.br

3 Profs. Drs. do Dept ${ }^{\circ}$ de Zootecnia, Universidade Estadual de Londrina, UEL, Londrina, PR. E-mail: maafbarbosa@uel.br; leandro@uel.br; dudabumbieris@hotmail.com; anapaula_fortaleza@yahoo.com.br

4 Mestre em Ciência Animal, UEL, Londrina, PR. E-mail: leticiacastro@zootecnista.com.br

5 Profs. Drs. do Dept ${ }^{\text {o }}$ de Zootecnia, UEL, Bolsista de Produtividade do CNPq. Londrina, PR. E-mail: elar@uel.br; mizubuti@uel.br Autor para correspondência 


\section{Introdução}

O Brasil possui posição de destaque no cenário mundial de produção de carne bovina, tornando este setor de extrema importância à economia do país (SILVEIRA; BURNQUIST, 2009). Outro setor do agronegócio nacional que apresenta constante crescimento é o campo da agricultura energética, liderado pela cana-de-açúcar, matéria prima na produção do etanol (LEITE et al., 2011). Impulsionada pela demanda energética, a indústria dos biocombustíveis proporcionam aos pecuaristas atrativa remuneração por hectare, avançando sobre as áreas de pastagens. A produção de bovinos de corte no Brasil faz dos pastos a principal fonte de alimento dos rebanhos (CASTRO et al., 2010), caracterizando a pecuária de corte nacional por custos de produção relativamente baixos, porém com índices produtivos abaixo do potencial (BARONI et al., 2010).

O manejo das pastagens é o conjunto de ações buscando produzir forragem de forma eficiente em quantidade e qualidade nutricional para os animais, e tem como principal objetivo conciliar condições favoráveis à fisiologia e desenvolvimento da planta forrageira sob pastejo, com o desempenho e produção de carne bovina por hectare (BARBOSA; NASCIMENTO JÚNIOR; CECATO, 2006). Entre as forrageiras tropicais, as excelentes características agronômicas e nutricionais destacam o capim Tanzânia (Panicum maximum Jacq. cv. Tanzânia) para utilização na pecuária de corte.

Silva e Nascimento Júnior (2007) discutiram a elaboração de estratégias de manejo das pastagens utilizando metas de altura do pastejo, que é a mensuração da altura do dossel forrageiro (realizadas na curvatura das lâminas foliares superiores) como ferramenta para direcionar o pastejo dos animais, buscando eficiência de colheita da forragem produzida. A partir desta premissa, a altura do pasto pode orientar a entrada ou saída de animais de uma determinada área com sistema de lotação rotacionada das pastagens, ou ainda a inclusão ou remoção de animais adicionais em sistemas de lotação contínua.

A realização de análise econômica de um sistema pecuário é de fundamental importância para elaboração de estratégias visando eficiência na utilização dos recursos disponíveis, e redução dos riscos operacionais na tomada de decisões e investimentos. Embora os resultados financeiros sejam fundamentados em índices zootécnicos e resultados biológicos, a correlação entre ambos nem sempre caminha para a mesma direção (GUIMARÃES et al., 2005). O objetivo deste trabalho foi avaliar os resultados econômicos do manejo de capim Tanzânia sob quatro intensidades de pastejo por bovinos de corte sob lotação contínua.

\section{Material e Métodos}

Os dados analisados são provenientes de resultados biológicos obtidos em uma propriedade agropecuária comercial, em Cidade Gaúcha, Noroeste do Estado do Paraná, com $550 \mathrm{~m}$ de altitude, com relevo levemente ondulado. Segundo a classificação de Köppen o clima da região é Cfa, e as condições climáticas são apresentadas na Figura 1. O período considerado no fluxo de caixa foi compreendido entre janeiro e dezembro de 2010. Análise química do solo à camada arável apresentou os resultados: $\mathrm{pH}$ em água $=6,03 ; \mathrm{Ca}^{+2}=1,74 \mathrm{cmol} /$ $\mathrm{dm}^{3} ; \mathrm{Mg}^{+2}=0,52 \mathrm{cmol} / \mathrm{dm}^{3} ; \mathrm{K}^{+}=0,23 \mathrm{cmol} / \mathrm{dm}^{3}$; $\mathrm{Na}^{+}=0,00 \mathrm{cmol} / \mathrm{dm}^{3} ; \mathrm{P}$ disponível $=2,36 \mathrm{mg} / \mathrm{dm}^{3}$; CTC efetiva $=2,49 \mathrm{cmol} / \mathrm{dm}^{3} ;$ e $\mathrm{Al}=0,00 \%$.

O trabalho realizado comparou o retorno econômico de quatro métodos de manejo do pastejo sob lotação contínua por bovinos de corte, com taxa de lotação variável, visando manutenção da altura do dossel forrageiro em pastos de capim Tanzânia nas alturas de 20;40;60 e $80 \mathrm{~cm}$, onde a altura média inicial dos piquetes foi de $78,76 \mathrm{~cm} \pm 5,28$, com ajuste da taxa de lotação animal até atingir a altura pretendida. A área total foi de 12 hectares, dividida em 12 piquetes de um hectare cada, com três repetições por tratamento. Para manutenção das 
alturas foram utilizados três bovinos por piquete, machos, Nelore, com peso vivo médio inicial de 340 quilogramas, castrados e vermifugados, com introdução de animais adicionais conforme necessidade de ajuste às alturas pretendidas.

Figura 1. Precipitação pluviométrica (Pp), temperatura média máxima $\left({ }^{\circ} \mathrm{C}\right.$ Max.) e mínima $\left({ }^{\circ} \mathrm{C}\right.$ mín.), seguidas pelas médias e desvios, no ano de 2010, no Noroeste do Paraná. Fonte: SIMEPAR.

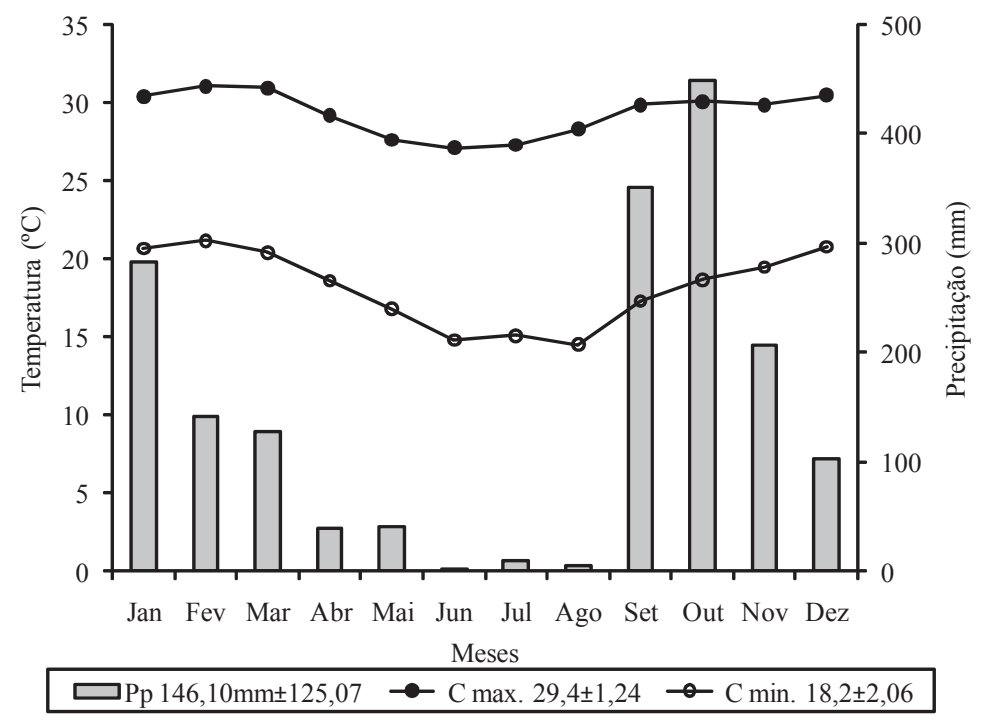

Fonte: (SIMEPAR, 2012).

A altura do dossel foi mensurada em 20 pontos aleatórios por piquete a cada 14 dias na curvatura das lâminas foliares superiores, com régua graduada em centímetros. Os animais foram pesados no início do período experimental e a cada 28 dias após jejum alimentar e hídrico de 12 horas, para controle da taxa de lotação (UA ha-1), e de acordo com a necessidade de ajuste para manutenção das alturas, animais adicionais eram introduzidos ou retirados, conforme metodologia descrita por Mott e Lucas (1952), e pela diferença entre o peso corporal inicial e final, foi calculado o ganho por hectare $\left(\mathrm{kg} \mathrm{ha}^{-1}\right)$, considerando dois fluxos de caixa. As receitas do primeiro fluxo foram obtidas com o abate dos animais em agosto de 2010, e a segunda considerando $52 \%$ de rendimento de carcaça em dezembro (obtido no abate dos animais terminados no mês de agosto).

O valor do imóvel territorial considerado foi o preço médio praticado em áreas de pastagens na região Noroeste do Paraná de R\$ 8100,00 ha-
1, obtidos por levantamentos de Lopes e Torres Júnior (2010). Os custos referentes às benfeitorias, maquinários e equipamentos foram cotados de acordo com valores comerciais vigentes no período experimental, a depreciação foi calculada considerando vida útil referente a cada equipamento ou instalação, de acordo com descrito por Pilau, Rocha e Santos (2003).

Os custos de implantação e manutenção dos pastos foram computados como investimentos na alimentação e nutrição do rebanho à durabilidade de cinco anos, sendo considerados valores cotados em casas agropecuárias comerciais, onde também foram determinados custos referentes à sanidade do rebanho e demais insumos utilizados. Para mão de obra; tributos fiscais e despesas administrativas foram considerados os valores reais praticados na propriedade. Todos os investimentos foram ponderados de acordo com a área, rebanho e/ou período de utilização (FRANK, 1978; NOGUEIRA, 2007). 
As taxas de juros consideradas sobre o capital investido foram de seis pontos percentuais ao ano, valor referência de rentabilidade da caderneta de poupança, sendo também utilizado como taxa mínima de atratividade da atividade pecuária (PERES et al., 2005). O valor presente líquido foi calculado pela equação:

$$
\begin{gathered}
n \\
V P L=\sum_{t=0} V F /(1+r)^{t}
\end{gathered}
$$

Onde: $\mathrm{VPL}=$ valor presente líquido; $\mathrm{VF}=$ valor do fluxo de caixa líquido (diferença entre entradas e saídas); $\mathrm{n}=$ número de fluxos; $\mathrm{r}=$ taxa de desconto e $\mathrm{t}=$ tempo de análises.

Após o VPL, foi calculada a taxa interna de retorno do capital investido (TIR) para obtenção do ponto nulo de VPL, ou seja, igual a zero. A obtenção deste parâmetro, quando superior a zero, demonstra viabilidade econômica positiva.

$\mathrm{VPL}=\mathrm{VF} 0+\{\mathrm{VF} 1 /(1+\mathrm{r}) 1\}+\{\mathrm{VF} 2 /$ $(1+\mathrm{r}) 2\}+\{\mathrm{VF} 3 /(1+\mathrm{r}) 3\}+\ldots\{\mathrm{VFn} /(1+\mathrm{r}) \mathrm{n}\}$

Onde VF $=$ valor do fluxo de caixa líquido $(0,1$, $2,3, \ldots, n)$ e $r=$ taxa de desconto. Foi determinada a lucratividade e rentabilidade de cada sistema, utilizando metodologia proposta por Frank (1978).

Os tributos fiscais foram computados proporcionalmente à área utilizada, sendo o Funrural de 2,3\%, e o Imposto de Renda calculado com auxílio de planilha eletrônica disponível na página eletrônica da receita federal (BRASIL, 2011), ambos levando em consideração os valores reais obtidos com as receitas de produção de cada sistema de pastejo.

O delineamento estatístico foi inteiramente casualizado, com três repetições por tratamento, onde cada piquete representou uma unidade experimental. Os resultados obtidos foram submetidos à análise de variância $(\mathrm{P}<0,05)$ e dependendo dos resultados, foram realizados procedimentos de regressão para determinação do efeito das alturas de pastejo, onde os modelos matemáticos foram escolhidos de acordo com a significância do coeficiente de regressão e coeficientes de determinação.

\section{Resultados e Discussão}

O peso de abate dos animais no mês de agosto foi de 474,66 $\pm 29 ; 483 \pm 31 ; 455,33 \pm 14$ e $489 \pm 17 \mathrm{~kg}$ (não significativo, onde: $\mathrm{P}>0,10$ ) e o ganho de peso corporal por hectare nos demais meses até dezembro foi de $290,33 \pm 57,93 ; 282,47 \pm 45,54 ; 255,00 \pm 33,06$ e $233,33 \pm 38,99 \mathrm{~kg}$ ( $\mathrm{y}=327,000-1,113333 \mathrm{x} ; \mathrm{r}^{2}=0,75$; $\mathrm{P}=0,025)$ para os pastos de $20 ; 40 ; 60$ e $80 \mathrm{~cm}$ respectivamente. A taxa de lotação das pastagens, expressa em unidade animal por hectare (UA ha $\left.{ }^{-1}\right)$ apresentou comportamento quadrático em função das alturas de pastejo, demonstrando a necessidade de maior intensidade de desfolha para manutenção do relvado mais baixo. A taxa de lotação média anual e o ganho de peso corporal por hectare constam na Figura 2.

A produção de peso corporal por hectare apresentou comportamento linear negativo em função das alturas de pastejo. Euclides et al. (2007), apontam que oaumento da capacidade taxa de lotação, é o fator determinante na viabilidade de sistemas pecuários, resultando em maior produtividade e rentabilidade financeira. Os custos e despesas operacionais dos componentes de produção podem ser observados na Tabela 1. Podemos observar nas quatro intensidades de pastejo, os mesmos valores praticados para o imóvel territorial; benfeitorias; maquinário e equipamentos; mão de obra e despesas administrativas, devido ao fato da mesma área de produção utilizada nos quatros sistemas estudados.

$\mathrm{Na}$ ocasião de aquisição do rebanho, o preço de compra foi de R\$739,90 por novilho. Este valor foi submetido a uma taxa de juros de seis pontos percentuais ao ano. O valor médio de comercialização por hectare de pastagem na região Noroeste do Paraná no ano de 2010 foi de R\$ $8.100,00$, segundo levantamentos realizados por Lopes e Torres Júnior (2010). 
Figura 2. Produção anual de peso corporal por hectare (Pha) e taxa de lotação média anual por hectare (Lha) por bovinos de corte em função da altura de pastejo de capim Tanzânia. Fonte: Resultados, Cidade Gaúcha, PR (2010).

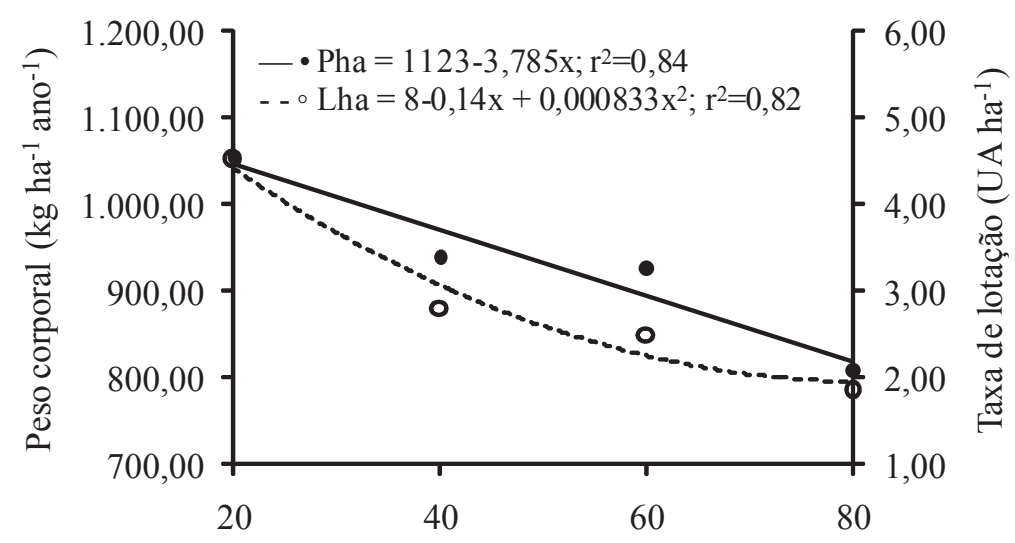

Altura $(\mathrm{cm})$

Fonte: Elaborado pelos autores.

Quando são utilizados indicadores econômicos que levam em consideração o capital investido na atividade, o valor do imóvel apresenta influência significativa (GUIMARÃES et al., 2005), principalmente pelo elevado valor do imóvel rural praticado em algumas regiões brasileiras, em muitos casos não sendo compatível com sistemas pecuários ditos como tradicionalistas, que geralmente fazem uso de grandes dimensões de terras com baixa produtividade (LOPES; TORRES JÚNIOR, 2010). Ainda segundo os autores, o Brasil apresenta perspectivas de constante crescimento quanto ao mercado de terras e valorização de imóveis rurais, exigindo cada vez mais eficiência de produção para se obter retorno econômico.

O percentual de participação de cada componente de produção consta na Tabela 1 . O valor sobre o imóvel apresentou comportamento linear positivo em função das alturas do dossel forrageiro, resultantes das menores taxas de lotação quando o objetivo foi manutenção de maiores alturas do pasto. Foi observado comportamento contrário, ou seja, linear negativo na participação do capital sobre o valor do rebanho, fato explicado pela necessidade de menor número de animais, menor capital inicial de aquisição e consequentemente menor taxas de juros atribuídas para menores taxas de lotação nas maiores alturas.

Foi observado comportamento linear positivo em função da altura do pasto em todas as situações de custos ou despesas fixos de produção na participação dos componentes de produção: benfeitorias; equipamentos e maquinários; mão de obra e despesas administrativas (Tabela 1).

Por se tratarem de custos ou despesas fixas, quando ocorre o aumento da escala de produção, a proporção do valor total é diluída pelas unidades de produto gerado, reduzindo sua participação no custo final de produção. Esse comportamento sugere que a pecuária de corte se comporta como atividade econômica dependente de escala de produção, principalmente pelo alto capital necessário para aquisição dos recursos de produção. 


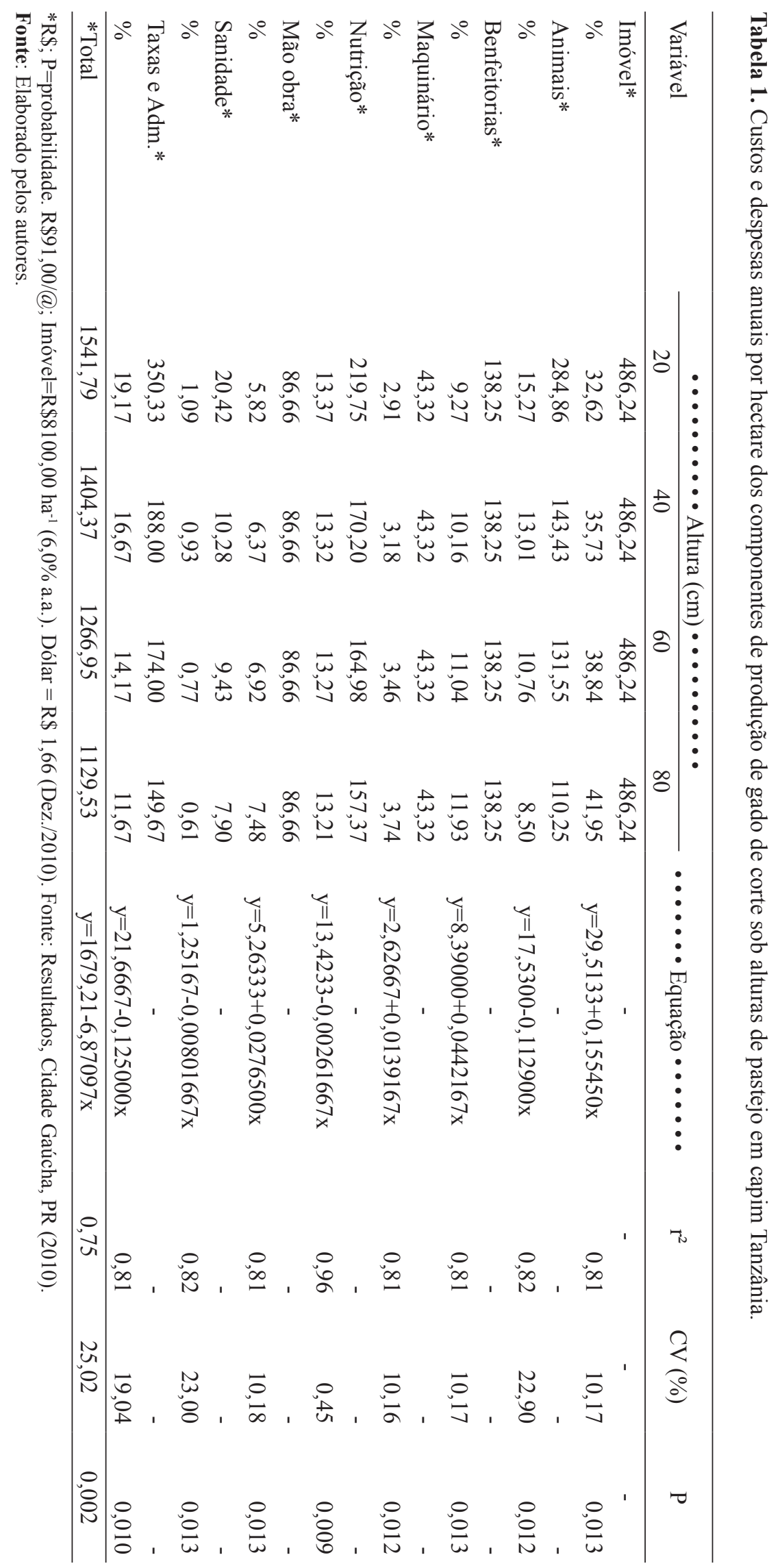


Portanto, sistemas que apresentam baixa escala de produção, tendem apresentar custo unitário de produção mais elevado (PERES et al., 2005). Neste contexto, a aplicação de técnicas de manejo pode representar custos adicionais por unidade produzida, mas quando apresentam resultados biológicos favoráveis, podem amortizar os custos fixos constituídos por gastos com serviços administrativos, impostos, depreciações de máquinas e implementos, aumentando a lucratividade da empresa pecuária (PILAU; ROCHA; SANTOS, 2003).

A participação total dos custos variáveis apresentou comportamento linear negativo, sendo eles: nutrição; sanidade e tributos fiscais. Segundo Bittencourt, Lôbo e Bezerra (2006), os custos com alimentação dos rebanhos pode atingir 70\% do custo total de produção de bovinos de corte, havendo demasiada redução da participação deste componente em sistemas exclusivamente a pasto, recebendo apenas mistura mineral. A participação da sanidade no custo final de produção pode ser altamente influenciável pelos investimentos em medidas profiláticas. Segundo Silveira e Burnquist (2009), quando um manejo profilático é realizado de forma adequada, os gastos são ínfimos, se tornando um investimento com grande resultado quando comparado às despesas clínicas.

Os custos de implantação e manutenção da forrageira foram computados entre as despesas com a nutrição e alimentação do rebanho. Deve ser levado em consideração que, um fator negativo decorrente da taxa de lotação acima do potencial das pastagens ou super pastejo, é a degradação das pastagens, podendo exaurir as reservas de nutrientes do solo, e gerar alterações prejudiciais à sua estrutura física, geralmente resultando ainda em elevados custos para recuperação (DIAS FILHO, 2011).

O custo de produção por hectare apresentaram comportamento linear negativo em função das intensidades de pastejo. Este resultado é explicado devido ao fato que, para manutenção do dossel forrageiro mais elevado, é necessário menor número de animais, e consequentemente, menor capital investido na taxa de juros e na aquisição do rebanho.

O custo de produção por hectare é um fator determinante no resultado econômico de uma atividade agropecuária, exercendo forte impacto sobre a margem de lucro em operação. Sistemas pecuários com elevados custos de produção e reduzidas margens de lucro tendem a perder competitividade, principalmente com o setor de biocombustíveis, em crescente avanço sobre as áreas pecuárias no Brasil (LEITE et al., 2011).

Os quatro sistemas de pastejo analisados não apresentaram diferenças para o lucro líquido anual por hectare; custo por arroba de carcaça produzida; lucro líquido por arroba de carcaça produzida e lucro médio mensal por unidade animal. Também não foram observadas diferenças significativas para os indicadores econômicos: valor presente líquido; taxa interna de retorno; lucratividade e rentabilidade (Tabela 2).

Cotações levantadas em frigoríficos da região Noroeste do Paraná apontaram preço médio (ponderado pelo equivalente carcaça abatido e estimado) praticado nos meses de agosto e dezembro de 2010, de R\$91,00 pela arroba de animais terminados, período de fechamento dos fluxos de caixa, sendo estes valores tomados como base para as receitas na análise econômica realizada. Análise das cotações de insumos e arroba do boi gordo comercializadas no ano de 2010 revelou este, um ano extremamente positivo à pecuária de corte, fator este que possivelmente favoreceu tais resultados econômicos (SILVA; AGUIAR; GOULART, 2010). Porém, em posse dos resultados biológicos é possível, em qualquer outro período, desde que não sofra demasiados efeitos das condições climáticas, realizar a extrapolação e atualização das cotações agropecuárias para estudo da viabilidade da pecuária de corte sob intensidade de pastejo. 
Tabela 2. Lucro líquido por hectare (LLH), custo por arroba produzida (CPA), lucro líquido por arroba (LLA), lucro mensal por unidade animal (LMU), valor presente líquido (VPL) dados em reais (R\$), taxa interna de retorno (TIR), lucratividade média mensal (LUC) e rentabilidade média mensal (REN) dados em percentual, na produção de bovinos de corte em função das alturas de pastejo do capim Tanzânia.

\begin{tabular}{|c|c|c|c|c|}
\hline & $\begin{array}{c}\cdots \cdots \cdots \cdots \cdots \\
20\end{array}$ & $\begin{array}{c}\cdots \\
40\end{array}$ & 60 & 80 \\
\hline LLH* $^{*}$ & $1215,30 \pm 400,16$ & $1220,14 \pm 285,22$ & $1203,44 \pm 488,20$ & $886,10 \pm 904,31$ \\
\hline $\mathrm{CPA}^{*}$ & $57,85 \pm 10,60$ & $53,96 \pm 4,88$ & $54,61 \pm 9,44$ & $64,81 \pm 23,12$ \\
\hline LLA* & $33,15 \pm 10,60$ & $37,04 \pm 4,88$ & $36,39 \pm 9,44$ & $26,19 \pm 23,12$ \\
\hline LMU* & $20,88 \pm 14,57$ & $31,49 \pm 3,68$ & $34,20 \pm 15,35$ & $28,74 \pm 27,19$ \\
\hline VPL* & $491,81 \pm 388,15$ & $575,44 \pm 212,33$ & $568,32 \pm 381,25$ & $331,83 \pm 703,89$ \\
\hline TIR* & $0,38 \pm 0,16$ & $0,44 \pm 0,09$ & $0,44 \pm 0,17$ & $0,33 \pm 0,33$ \\
\hline LUC* & $3,04 \pm 0,97$ & $3,39 \pm 0,45$ & $3,33 \pm 0,86$ & $2,40 \pm 2,12$ \\
\hline REN* & $5,05 \pm 2,23$ & $5,70 \pm 1,21$ & $5,83 \pm 2,39$ & $4,40 \pm 4,43$ \\
\hline
\end{tabular}

*Não significativo $(\mathrm{P}>0,05)$. Dólar = R\$ 1,66 (Dez./2010). Fonte: Resultados, Cidade Gaúcha, PR (2010).

Fonte: Elaborado pelos autores.

A taxa interna de retorno é a taxa de juros que iguala o valor presente líquido de um projeto a zero, sendo a taxa de desconto que iguala o valor presente dos benefícios de um projeto ao valor presente de seus custos. Assim, a atividade apresentará viabilidade quando a taxa interna de retorno for igual ou maior que o custo de oportunidade referente ao capital investido (CONTADOR, 1988).

A taxa interna de retorno obtidas nos quatro sistemas de pastejo pode ser considerada atrativa, pois apresentaram remuneração do capital investido muito maior do que a taxa mínima de atratividade, neste caso, considerada a caderneta de poupança, tida como referência à investimentos financeiros (PERES et al., 2005). Após a análise realizada, os quatro sistemas de pastejo estudados apresentam atratividade e viabilidade econômica.

\section{Conclusões}

Não foram constatadas diferenças significativas quanto às intensidade de desfolha do capim Tanzânia sobre os indicadores econômicos calculados, sendo que em todos os casos o sistema remunerou o capital investido. Existe a necessidade de estudos sobre os efeitos em longo prazo, devido à possibilidade de degradação das pastagens e referentes custos de recuperação.

\section{Referências}

BARBOSA, M. A. A. F.; NASCIMENTO JÚNIOR, D.; CECATO, U. Dinâmica da pastagem e desempenho de novilhos em pastagem de capim-tanzânia sob diferentes ofertas de forragem. Revista Brasileira de Zootecnia, Viçosa, MG, v. 35, n. 4, p. 1594-1600, 2006.

BARONI, C. E. S.; LANA, R. P.; MANCIO, A. B.; MENDONÇA, B. P. C.; LEÃO, M. I.; SVERZUT, C. B. Consumo e digestibilidade de nutrientes em novilhos suplementados e terminados em pasto, na seca. Arquivo Brasileiro de Medicina Veterinária e Zootecnia, Belo Horizonte, v. 62, n. 2, p. 365-372, 2010.

BITTENCOURT, T. C. C.; LÔBO, R. B.; BEZERRA, L. A. F. Objetivos de seleção para sistemas de gado de corte em pasto: ponderadores econômicos. Arquivo Brasileiro de Medicina Veterinária e Zootecnia, Belo Horizonte, v. 58, n. 2, p. 196-204, 2006.

BRASIL. Receita Federal. Simulação de Alíquota efetiva 2011. 2011. Disponível em: $<\mathrm{http} / / / \mathrm{www} . r e c e i t a f e d e r a l$. gov.br>. Acesso em: 21 jan. 2011.

CASTRO, G. H. F.; RODRIGUEZ, N. M.; GONÇALVES, L. C.; MAURÍCIO, R. M. Características produtivas, agronômicas e nutricionais do capim-tanzânia em cinco diferentes idades ao corte. Arquivo Brasileiro de Medicina Veterinária e Zootecnia, Belo Horizonte, v. 62, n. 3, p. 654-666, 2010.

CONTADOR, C. R. Indicadores para seleção de projetos. In: _. Avaliação social de projetos. 2. ed. São Paulo: Atlas, 1988. p. 41-58.

DIAS FILHO, M. B. Os desafios da produção animal em pastagens na fronteira agrícola brasileira. Revista 
Brasileira de Zootecnia, Viçosa, MG, v. 40, p. 243-252, 2011. Suplemento Especial.

EUCLIDES, V. B. P.; COSTA, F. P.; MACEDO, M. C. M.; FLORES, R.; OLIVEIRA, M. P. Eficiência biológica e econômica de pasto de capim-Tanzânia adubado com nitrogênio no final do verão. Pesquisa Agropecuária Brasileira, Brasília, v. 42, n. 9, p. 1345-1355, 2007.

FRANK, R. G. Introducción al calculo de costos agropecuarios. Buenos Aires: El ateneo, 1978.

GUIMARÃES, P. H. S.; MADALENA, F. E.; CESAR, I. M. Simulação dos efeitos dos preços de produtos e insumos na avaliação econômica de três sistemas alternativos de bovinocultura de cria. Arquivo Brasileiro de Medicina Veterinária e Zootecnia, Belo Horizonte, v. 57, p. 227-230, 2005. Suplemento 2.

LEITE, G. H. P.; CRUSCIOL, C. A. C.; SILVA, M. A. Desenvolvimento e produtividade da cana-de-açúcar após aplicação de reguladores vegetais em meio de safra. Sêmina: Ciências Agrárias, Londrina, v. 32, n. 1, p. 129138, 2011.

LOPES, R. V.; TORRES JÚNIOR, A. Relatório de terras: análise de mercado. Bebedouro: Scot Consultoria, 2010. v. 1, n. 2,24 p.

MOTT, G. O.; LUCAS, H. L. The design conduct and interpretation of grazing trials on cultivated and improved pastures. In: INTERNATIONAL GRASSLAND CONGRESS, 6., 1952, Pensylvania. Anais... Pensylvania: State College, 1952. p. 1380-1395.

NOGUEIRA, P. M. Gestão de custos e avaliações de resultados. Bebedouro: Scot Consultoria, 2007. 244 p.
PERES, A. A. C.; VASQUEZ, H. M.; SILVA, J. F. C.; SOUZA, P. M.; SOARES, C. S.; BARROS, S. C. W.; MORENZ, M. J. F.; DETMANN, E. Avaliação produtiva e econômica de sistemas de produção bovina em pastagens de capim-elefante. Arquivo Brasileiro de Medicina Veterinária e Zootecnia, Belo Horizonte, v. 57, n. 3, p. 367-373, 2005.

PILAU, A.; ROCHA, M. G.; SANTOS, D. T. Análise econômica de sistemas de produção para recria de bezerras de corte. Revista Brasileira de Zootecnia, Viçosa, MG, v. 32, n. 4, p. 966-976, 2003.

SILVA, A. S. L. da; AGUIAR, G. A. M.; GOULART, R. Boi \& companhia: informativo pecuário semanal. Bebedouro: Scot Consultoria, 2010. v. 17, n. 900, 18 p.

SILVA, S. C. da; NASCIMENTO JÚNIOR, D. Avanços na pesquisa com plantas forrageiras tropicais em pastagens: características morfofisiológicas e manejo do pastejo. Revista Brasileira de Zootecnia, Viçosa, MG, v. 36, p. 122-138, 2007. Suplemento 1.

SILVEIRA, L. T.; BURNQUIST, H. L. Procedimento para análise de decisão quanto à prevenção de doenças em animais: uma aplicação da Teoria dos Jogos. Revista de Economia e Sociologia Rural, Brasília, v. 47, n. 2, p. 435-464, 2009.

SISTEMA METEOROLÓGICO DO PARANÁ SIMEPAR. 2012. Disponível em: <http://www.simepar. br>. Acesso em: 28 nov. 2012. 
